\section{Lightwand intubation: II - Clinical trial of a new lightwand for tracheal intubation in patients with difficult airways}

Orlando R. Hung MD, Saul Pytka MD, Ian Morris MD, Michael Murphy MD* Ronald D. Stewart MD*
Lightwands have been used to assist in the tracheal intubation of patients with difficult airways for many years. A new lightwand (Trachlight $(i)$ ) with a brighter light source and a flexible stylet permits both oral and nasal intubation under ambient light. This study reports the effectiveness of the Trachlight $\mathrm{(IS}$ in tracheal intubation in patients with difficult airways. Two groups of patients were studied: Group 1 - patients with a documented history of difficult intubation or anticipated difficult airways; Group 2 - anaesthetized patients with an unanticipated failed laryngoscopic intubation. In Group 1, the tracheas were intubated using the Trachlight $($ ) with patients either awake or under general anaesthesia. In Group 2, tracheas were intubated under general anaesthesia using the Trachlight (i). The time-to-intubation, number of attempts, failures, and complications during intubation for all patients were recorded. Two hundred and sixty-five patients were studied with 206 patients in Group 1, and 59 in Group 2. In most patients, the tracheas were intubated orally (183 versus 23 nasal) during general anaesthesia (202 versus 4 awake) in Group 1. Intubation was successful in all but two of the patients with a mean $( \pm S D)$ timeto-intubation of $25.7 \pm 20.1 \mathrm{sec}$ (range 4 to $120 \mathrm{sec}$ ). The tracheas of these two patients were intubated successfully using

\section{Key words}

ANESTHETIC EQUIPMENT: lightwand, lighted-stylet,

fibreoptic bronchoscope;

INTUBATION, TRACHEAL: lightwand, technique.

From the Departments of Anaesthesia and Emergency Medicine*, Dalhousie University, Halifax, Nova Scotia, Canada.

Address correspondence to: Dr. Orlando R. Hung,

Department of Anaesthesia, Victoria General Hospital,

Halifax, Nova Scotia, Canada, B3H 2 Y9.

Supported, in part, by a Grant from Laerdal Research

Foundation, Armonk, NY.

Accepted for publication 15th May, 1995. a fibreoptic bronchoscope. Orotracheal intubation was successful in all patients in Group 2 using the Trachlight $(\mathbb{1}$ with a mean ( $\pm S D$ ) time-to-intubation of $19.7 \pm 13.5 \mathrm{sec}$. Apart from minor mucosal bleeding (mostly from nasal intubation), no serious complications were observed in any of the study patients. With proper preparation, this study has demonstrated that Trachlight ${ }^{\oplus}$ is an effective and safe device to intubate the tracheas of elective surgical patients with a history of difficult airway in experienced hands.

Le mandrin lumineux est utilisé pour faciliter lintubation de la trachée depuis plusieurs années. Un nouveau mandrin lumineux (Trachlight ${ }^{\oplus}$ ) avec une source lumineuse plus intense et un stylet flexible permet lintubation orale et nasale à la lumière ambiante. Cette étude porte sur l'efficacité du Trachlight ${ }^{(14}$ pour l'intubation trachéale de patients à voies aériennes difficiles d'accès. Deux groupes de patients sont étudiés: le groupe 1 est constitué de patients dont les antécédents dintubation difficile sont documentés ou chez qui on anticipe un accès difficile aux voies aériennes; le groupe 2 comprend des patients dont lintubation par laryngoscope a échoué inopinément. Dans le groupe 1, la trachée est intubée avec le Trachlight ${ }^{(10}$ alors que le patient est éveillé ou complètement anesthésié. Dans le groupe 2, la trachée est intubée sous anesthésie générale avec le Trachlight ${ }^{(}$. Le temps requis pour lintubation, le nombre de tentatives, les échecs et les complications survenant pendant lintubation sont notés chez tous les patients. Deux cent soixante-cinq patients sont inclus dans létude, dont 206 dans le groupe 1 et 59 dans le groupe 2. Pour la plupart des patients du groupe 1, la trachée est intubée par la voie orale (183 vs 23 par le nez) pendant une anesthésie générale (202 vs 4 éveillés). Lintubation réussit dans tous les cas à l'exception de deux. La moyenne ( $\pm E T$ ) pour la durée de lintubation est de $25,7 \pm 20,1 \mathrm{sec}$ (de 4 à $120 \mathrm{sec}$ ). En ce qui concerne les deux échecs, lintubation est réussie plus tard grâce à la fibroscopie. Lintubation orotrachéale est réussie chez tous les patients du groupe 2 avec le Trachlight ${ }^{\oplus}$ et la moyenne pour la durée de lintubation est de 19,7 $\pm 13,5$ sec. A l'ex- 
ception de saignements muqueux légers (causés surtout par l'intubation nasale), on n'observe pas de complications graves parmi les patients de cette étude. Avec une préparation appropriée, cette étude montre que le Trachlight ${ }^{(i 0}$ constitue, pour des personnes d'expérience, un outil efficace et sûr pour intuber la trachée de patients programmés qui possèdent des voies aériennes d'accès difficile.

It has been estimated that between one and three per cent of surgical patients have "difficult airways," making laryngoscopic intubation difficult and sometimes impossible. ${ }^{1}$ Because of these difficulties, many alternative intubating techniques have been developed and tested over the past several decades including lighted-stylets (lightwands). Many studies have reported the successful use of lightwands in the tracheal intubation of patients with difficult airways. ${ }^{2-4}$ However, Ainsworth commented that a dark environment was necessary for the optimal use of the device. ${ }^{4}$ Recent technological improvements and past clinical experience have permitted the development of a transilluminating instrument designed specifically for tracheal intubation. A new design of the lightwand device (Trachlight $\oplus$, Laerdal Medical Corp., Armonk, NY) has incorporated modifications to make it suitable for both oral and nasal intubation. ${ }^{5}$ It has a brighter light source to allow intubation under ambient lighting, an adjustable wand length to accommodate either a cut or full length endotracheal tube, and a retractable internal stiff stylet to increase flexibility of the device for both oral and nasal intubation. The data from our preliminary study have demonstrated the efficacy and safety of the device for tracheal intubation of elective surgical patients. ${ }^{6}$ In addition, there is no relationship between the ease of intubation using the Trachlight(1) and anatomical variations of the upper airways of patients, suggesting that the device may be an effective alternative for patients with a documented history of difficult laryngoscopic intubation. This study reports the effectiveness of the Trachlight $(10)$ in tracheal intubation in patients with documented difficult intubation or failed laryngoscopic intubation.

\section{Methods}

All investigators were experienced with the use of Trachlight (iT). Following the approval of the institutional review board and informed consent, two groups of patients were studied: Group 1 - patients with a documented history of difficult intubation or anticipated difficult airways determined during preoperative airway assessment; Group 2 - patients after a failed laryngoscopic intubation during general anaesthesia, who had unremarkable preoperative assessment of their airways.
Study design for patients in Group 1

During a 24 mo.period, all adult elective surgical patients who were seen preoperatively by the investigators and were identified as having a history of difficult intubation or features suggestive of a difficult airway, such as cervical spine instability or restricted mouth opening were recruited. Exclusion criteria were uncooperative patients, patients requiring an emergency surgical procedure or patients who had a history of gastroesophageal reflux. All patients were informed of the use of the new intubating device (Trachlight(i)) for the placement of an endotracheal tube (ETT) into the trachea. An alternative technique using a fibreoptic bronchoscope would be used if the Trachlight $(1)$ technique was unsuccessful. All patients were given a choice of two anaesthetic techniques for intubation: (a) awake under topical anaesthesia; (b) asleep under general anaesthesia. All patients were informed of the advantages and risks of each of the anaesthetic techniques. Informed consent was obtained from all patients.

During the preoperative visit, with the patient resting in a semisitting position, the airway was assessed and the following measurements were made and recorded: (a) with the mouth widely open, the maximum distance between the upper and lower incisors or between the gingival margins in the edentulous; (b) the maximum distance of protrusion of the mandible relative to the maxilla; (c) the distance between the mentum and sternal notch with the neck in full flexion; (d) the distance between the mentum and sternal notch with the neck in full extension; (e) the distance between the mentum and hyoid bone; (f) the circumference of the neck at the laryngeal prominence. The pharyngeal structures were assessed with the patient's mouth widely opened as described by Mallampatti et al. ${ }^{7}$ The demographics such as age, sex, weight, and height were also recorded.

Upon arrival in the operating room, routine monitors, ECG, pulse oximetry and non-invasive blood pressure cuff were placed. Available in the operating room during the intubation was a difficult airway equipment cart containing many alternative intubating devices including the fibreoptic bronchoscope and the cricothyroidotomy kit.

For those patients who preferred to have the intubation whilst awake, topical anaesthesia was achieved as described previously. ${ }^{8}$ Briefly, topical anaesthesia of the oropharynx was achieved by gargling $30 \mathrm{ml}$ lidocaine $2-4 \%$. Anaesthesia of the remaining area of the pharynx, larynx and trachea was achieved by nebulizing 15 to $20 \mathrm{ml}$ tetracaine $0.45 \%$ with epinephrine via a DeVilbiss atomizer. Additional laryngeal anaesthesia was produced by transtracheal injection of $4 \mathrm{ml}$ lidocaine $2 \%$ using a 22-gauge needle as necessary. Sedation was achieved using intravenous midazolam $\left(0.01\right.$ to $\left.0.07 \mathrm{mg} \cdot \mathrm{kg}^{-1}\right)$ and/or propofol $\left(0.2\right.$ to $\left.1.5 \mathrm{mg} \cdot \mathrm{kg}^{-1}\right)$ during intubation. Tracheal 
intubation was then carried out using the Trachlight $($ IO. If the Trachlight (in) intubation was unsuccessful after three attempts, intubation was achieved using a fibreoptic bronchoscope as described previously. ${ }^{8}$

Patients who chose to have general anaesthesia for the tracheal intubation were preoxygenated for five minutes prior to induction of anaesthesia. Anaesthesia was induced with $1.5-2.5 \mathrm{mg} \cdot \mathrm{kg}^{-1}$ propofol $\dot{w}$. Following loss of consciousness, mechanical ventilation was provided via a face mask. If ventilation was felt to be difficult even in the presence of an oral or nasal airway or following appropriate repositioning of the head and neck, the patient was awakened and Trachlight $(10)$ intubation was then carried out awake under local anaesthesia. If mechanical ventilation was adequate, a muscle relaxant (1-1.5 $\mathrm{mg} \cdot \mathrm{kg}^{-1}$ succinylcholine or $0.1 \mathrm{mg} \cdot \mathrm{kg}^{-1}$ vecuronium) was administered. Tracheal intubation was then carried out using the Trachlight $(0$. Three attempts were permitted, with ventilation interposed. If the Trachlight ${ }^{\circ}$ intubation was unsuccessful after three attempts, intubation was carried out using a fibreoptic bronchoscope awake. The patient's heart rate and blood pressure, number of attempts, the time-to-intubation, failures and complications of the Trachlight $(10)$ intubation were recorded.

\section{Study design for patients in group 2}

Since the patients in this group did not have a history or any anatomical features suggestive of a difficult laryngoscopic intubation during the preoperative anaesthetic assessment, no informed consent was obtained from these patients. If, during general anaesthesia, laryngoscopic intubation wás unsuccessful (with different manoeuvres and blades) by experienced attending anaesthetists, one of the investigators experienced with the Trachlight(1) was called to assist the intubation using the Trachlight 1 . Three attempts were permitted, with oxygenation interposed. If this was unsuccessful, an alternative approach, such as awake fibreoptic intubation would be used. The number of attempts, failures, time-to-intubation, and complications during the Trachlight (Ti) intubation were reconded.

\section{Results}

Two hundred and sixty-five patients were studied with 206 patients in Group 1, and 59 in Group 2 (Table I).

\section{Group 1}

The features of difficult airways of this group are shown in Table II. Among the group with a history of difficult intubation, eight were also morbidly obese and four had Treacher Collins or Pierre Robin syndrome. The majority of the patients with ankylosed temporo-mandibular joints were scheduled for maxillo-facial surgery. In most pa-
TABLE I Demographics of patients.

\begin{tabular}{lrl}
\hline & Group I & \multicolumn{1}{c}{ Group 2 } \\
\hline Number of patients (M/F) & $206(115 / 91)$ & $59(28 / 31)$ \\
Age (yr) & $47.6 \pm 17.8$ & $53.1 \pm 16.7$ \\
Height (cm) & $165.5 \pm 10.8$ & $163 \pm 19.4$ \\
Weight (kg) & $76.4 \pm 25.0$ & $75.9 \pm 18.5$ \\
\hline
\end{tabular}

Mean \pm SD.

TABLE II Features of difficult airways of Group 1 patients

\begin{tabular}{ll}
\hline Features of difficult airwoys & Number of patients \\
\hline History of difficult intubation & 105 \\
Cervical spine instability & 64 \\
Ankylosed temporo-mandibular joints & 37 \\
\hline
\end{tabular}

tients, the trachea was intubated during general anaesthesia (202 patients) with only four patients being awake at intubation. The tracheal intubation was predominantly via the oral route ( 183 oral versus 23 nasal intubations).

Intubation was successful in all but two of the patients in Group 1 with a mean ( $\pm S D$ ) time-to-intubation of $25.7 \pm 20.1 \mathrm{sec}$ (range 4 to $120 \mathrm{sec}$ ). One of these failures was a morbidly obese patient $(220 \mathrm{~kg})$ who refused to have awake intubation. Under general anaesthesia, transillumination of the soft tissues of the neck was found to be impossible. The trachea of this patient was then intubated successfully using a fibreoptic bronchoscope whilst he was awake under topical anaesthesia. The second patient had a severe fixed flexion deformity of the cervical spine secondary to rheumatoid arthritis. Under general anaesthesia, transillumination was poor. Using extension of neck and jaw lift, the epiglottis could not be elevated away from the posterior wall of the pharynx, making it difficult to pass the Trachlight(if) under the epiglottis into the glottic opening. Because of the inability to elevate the epiglottis, awake fibreoptic intubation was also difficult, although this technique was eventually successful. Overall, apart from minor mucosal bleeding (mostly from nasal intubation), no serious complications were observed.

\section{Group 2}

Fifty-nine patients with no history of difficult airways had a failed laryngoscopic intubation during general anaesthesia (Tables I, II, III). Tracheal intubation was successful in all patients via the oral route using the Trachlight $(1)$ with a mean $( \pm S D)$ time-to-intubation of $19.7 \pm 13.5 \mathrm{sec}$ (range 5 to $75 \mathrm{sec}$ ). All but nine of these tracheal intubations were successful following one attempt. Apart from mucosal bleeding following multiple 
TABLE III Results and complications in both groups of patients

\begin{tabular}{lll}
\hline & Group 1 & Group 2 \\
\hline Number of patients & 206 & 59 \\
Time-to-intubation (sec) & $25.7 \pm 20.1$ & $19.7 \pm 13.5$ \\
Successful intubation following 1 attempt & 163 & 50 \\
Successful intubation following 2 or more & & \\
$\quad$ attempts & 43 & 9 \\
Number of patients with trauma & 32 & 23 \\
Number of patients with sore throat & 40 & 17 \\
\hline
\end{tabular}

unsuccessful laryngoscopic intubation attempts, no other complications were observed. Appropriate documentation and notification of the difficult laryngoscopic intubation were provided to all patients in this group postoperatively.

\section{Discussion}

The data have demonstrated that, with proper preparation, Trachlight ${ }^{+}$is an effective and safe tracheal intubating device for patients with difficult or failed laryngoscopic intubations either awake or under general anaesthesia. Even in the case of documented difficult airways, it was safe to induce general anaesthesia with a short-acting agent (propofol). Mechanical ventilation was ensured before a muscle relaxant was administered. Therefore, provided ventilation can be maintained, there appears to be little or no added risk in using this device under general anaesthesia, in view of its success and the short intubation time. The use of a short-acting anaesthetic agent ensured that the patient could be awakened quickly, if difficulties were encountered during intubation using the Trachlight ${ }^{(0)}$. The choice of anaesthetic technique should reflect the practice of the individual institution. Our technique (primarily general anaesthesia) should not be viewed as the recommended technique for patients with difficult airways.

Tracheal intubations were successful in all Group 2 patients (failed laryngoscopic intubation) using the Trachlight $(10.0$. This is probably a reflection of the investigators' experience since, collectively, the investigators had accumulated an experience of more than several thousand Trachlight $\odot$ intubations in "normal" elective surgical patients. Despite the apparent success and ease of use of the device, we recommend regular use so that proficiency and confidence can be maintained during "emergency" or "unprepared difficult" conditions. In this group of patients, the presence of secretions and blood in the oropharynx following multiple intubating attempts using a laryngoscope did not appear to affect the transillumination of the soft tissues of the anterior neck. The rapidity of intubation, the effectiveness of this device, and the ability to use the Trachlight $(10)$ in the presence of secretions and blood in this group of patients suggest that the Trachlight $(0)$ may play a major role in the initial management of patients with failed laryngoscopic intubation. In view of the small number of patients in this study, future studies are needed to confirm our findings.

There are several potential advantages of the Trachlight $(10)$ over other alternative intubating techniques such as intubation using a fibreoptic bronchoscope in patients with difficult airways. Fibreoptic intubation requires expensive equipment and special skills. Furthermore, this technique is difficult to use in emergency situations with "unprepared" and uncooperative patients or in patients with copious secretions or blood in the oropharynx. Because most Trachlight $(\mathrm{O})$ intubations can be achieved in seconds, even in these urgent unprepared cases, there is less likelihood of hypoxaemia, as reported in $25 \%$ of fibreoptic intubations. ${ }^{9}$ Apart from being safe and effective, intubation using the Trachlight is simple, and inexpensive.

Intubation using the Trachlight ${ }^{(0)}$ is a light-guided technique without visualization of the laryngeal structures. It should be used with caution or avoided in patients with abnormalities of the upper airways as described previously. ${ }^{5}$ There are potential risks of trauma to the upper airway associated with its use. However, intubation using the Trachlight $(10)$ is a gentle technique. The tip of the tube is withdrawn and redirected when resistance is felt. The gentleness of the technique is demonstrated by the low incidence of mucosal injury and the absence of dental trauma compared to laryngoscopy. ${ }^{6}$ Because of these potential benefits, intubation using the Trachlight (1) may be advantageous in patients with fixed dental appliances.

In summary, we have shown that intubation using the Trachlight ${ }^{-10}$ was effective, rapid, and safe in patients with difficult airways in experienced hands. The Trachlight (-) appears to be particularly useful as a first-line option in patients following a failed laryngoscopic intubation. It should be emphasized that regular use of the device in "normal" airways will improve proficiency with the lightwand technique and increase one's confidence when intubating more difficult cases.

\section{References}

1 Latto IP. Management of difficult intubation. In: Latto IP, Rosen M (Eds.). Difficulties in Tracheal Intubation. London: Ballière Tindall, 1987: 99-141.

2 Fox DJ, Matson MD. Management of the difficult pediatric airway in an austere environment using the lightwand. $\mathrm{J}$ Clin Anesth 1990; 2: 123-5.

3 Holzman RS, Nargozian CD, Florence B. Lightwand intubation in children with abnormal upper airways. Anesthesiology 1988; 69: 784-7. 
4 Ainsworth QP, Howell TH. Transilluminated tracheal intubation. Br J Anaesth 1989; 62: 494-7.

5 Hung OR, Stewart RD. Lightwand intubation: I. A new intubating device. Can J Anaesth 1995; 42: 820-5.

6 Hung OR, Pytka S, Morris I, et al. Clinical trial of a new lightwand (Trachlight $(\mathrm{O})$ ) to intubate the trachea. Anesthesiology (in press).

7 Mallampati SR, Gatt SP, Gugino LD, et al. A clinical sign to predict difficult tracheal intubation: a prospective study. Can Anaesth Soc J 1985; 32: 429-34.

8 Morris I. Fibreoptic intubation. Can J Anaesth 1994; 41 : 996-1008.

9 Cheng $D C H$, Asokumar B, Caballero $A C$, Wong $D$, Chung $F$. Haemodynamic, electrocardiographic and ventilatory changes during awake fibreoptic intubation. Can J Anaesth 1993; 40: A29. 